\title{
PRODUÇÃO DA CARNE CUNÍCULA NO BRASIL COMO ALTERNATIVA SUSTENTÁVEL
}

\author{
Andrei Bonamigo* \\ Cristiane Duarte** \\ César Augustus Winck ${ }^{* * *}$ \\ Simone Sehnem ${ }^{* * * *}$
}

RESUMO: O objetivo deste estudo foi identificar os subsídios necessários para tornar a produção da carne cunícula no Brasil uma alternativa sustentável. O aumento da demanda por produtos de origem animal desencadeou uma reorganização do setor de produção pecuária de forma a se readequar para suprir a demanda gerada. Esse cenário remete consequentemente aos mais variados impactos, especialmente no que tange ao meio ambiente. Diante dessa abordagem, a busca por produtos cárneos alternativos que promovam a redução desses impactos na natureza tornase importante, além do retorno econômico aos produtores. Por meio de análise de dados secundários, relacionados ao tema, o estudo apresentou, via matriz SWOT, os fatores envolvidos no desenvolvimento da cunicultura no Brasil e apontou a atividade como uma alternativa sustentável à pecuária tradicional com potencial para complementar a renda dos produtores e ser um alimento complementar das espécies tradicionais, produzidas e consumidas no Brasil.

PALAVRAS-CHAVE: Sustentabilidade, Agronegócio, Coelho, Alimentos alternativos, Pecuária sustentável.

\footnotetext{
Doutor em Engenharia de Produção pela Universidade Federal de Santa Catarina (UFSC). Mestre em Administração pela Universidade do Oeste de Santa Catarina (UNOESC). Docente na Universidade do Oeste de Santa Catarina (UNOESC). Brasil. E-mail: andreibonamigo@gmail.com

** Mestre em Administração (UNOESC). Pesquisadora na Linha de: Sustentabilidade em Organizações. Especialista em Marketing. Graduação em Administração de Empresas pela Unochapecó. Docente no Curso de Marketing no UNILASALLE Canoas (RS). Docente em cursos de Pós-Graduação/MBA, Brasil.

*** Doutor em Agronegócios pela Universidade Federal do Rio Grande do Sul (UFRGS). Docente e Pesquisador da Universidade do Oeste de Santa Catarina (UNOESC) no Mestrado Profissional em Administração. Docente no Centro Universitário Barriga Verde (UNIBAVE) e no Centro Universitário FacVest (FacVest), Brasil.

**** Doutora em Administraçãoe Turismo pela Univali/SC. Docente e Pesquisadora do Mestrado em Administração da Universidade do Sul de Santa Catarina (UNISUL) em Florianópolis/SC. Docente Permanente na Universidade do Oeste de Santa Catarina (UNOESC) no Mestrado Profissional em Administração
} 


\title{
PRODUCTION OF RABBIT MEAT IN BRAZIL AS SUSTAINABLE ALTERNATIVE FOOD
}

\begin{abstract}
Requirements for the production of rabbit meat in Brazil as a sustainable food alternative are provided. Increase in demand for animal-derived food triggered a reorganization of the cattle-breeding sector so that the demand may be satisfied. Frequently this implies in several impacts, especially with regard to the environment. Alternative meat products with a decrease in impacts are highly relevant and provide profit for producers. The analysis of secondary data related to the theme through SWOT matrix revealed factors in the development of rabbitbreading in Brazil and indicated the activity as a sustainable alternative to traditional cattle-breeding, featuring profit for producers and a supplementary food different from the traditional one normally produced and consumed in the country.
\end{abstract}

KEY WORDS: Sustainability, Agribusiness, rabbit, Alternative food, sustainable cattle-breeding.

\section{INTRODUÇÃO}

O consumo da carne de coelho no Brasil é considerado pequeno, já que o consumo médio está em torno de $0,12 \mathrm{~kg} / \mathrm{hab}$./ano, enquanto que outras carnes, como a bovina, chega a 37,4 kg/hab./ano e a de frango, a 43,9 kg/hab./ano (IBGE, 2011). Em aspectos de produção, a atividade cunícula também não tem representatividade, quando comparada com as tradicionais, diante do fato de que grande parte dos produtores trabalham com a cunicultura como atividade secundária, ou seja, de forma complementar (BONAMIGO, 2014).

Com manejo, alojamento e alimentação simples, a cunicultura possibilita rentabilidade ao produtor. $\mathrm{O}$ coelho pode ser explorado em diversas formas, pois a demanda de mercado possibilita que o produtor utilize o animal inteiro vivo ou já abatido, desde sua carne à sua pele, nada se perde (TVARDOVSKAS, 2012; SANTOS, 2010; ACBC, 2004; ICEA, 1969).

Produtos oriundos do coelho, como o sangue, que pode ser utilizado para produção de soro com grande aplicação na biotecnologia; do cérebro, de que pode ser obtida a tromboplastina; a pele, que pode ser utilizada na indústria de roupas; 
o couro, na produção de vestimentas como sapatos, carteiras e cintos; as vísceras, para a fabricação de farinha de carne para alimentação animal (ACBC, 2010). Esses produtos podem ser considerados alternativas de agregação de valor, capazes de tornar essa cadeia produtiva atraente para a agricultura familiar, produção em massa para atender às demandas crescentes da população mundial por produtos cárneos sem impactar no meio ambiente.

Além disso, a produção cunícula pode impactar positivamente na produção de alimentos brasileira e na mundial, a exemplo da possibilidade de exportação para outros países. Nessa perspectiva, para se ter uma noção do tamanho desse mercado, bem como possibilidades, de acordo com Colin (1992), há um grande consumo em países da CEE (Comunidade Econômica Europeia). Em alguns países europeus como Hungria, Polônia e República Tcheca, a produção de carne de coelhos destinase quase que por completa à exportação para os países da própria CEE, como Itália, França e Espanha, os quais, apesar de serem grandes produtores, pelo grande consumo interno acabam não sendo autossuficientes.

Já em relação ao Brasil, o efetivo de coelhos apresentou queda, em comparação às demais produções, de 12,4\% entre 2012 e 2011, tendo o registro de 204,831 mil animais no ano-base. O maior efetivo de coelhos encontra-se na região Sul do país, sendo os três Estados componentes desta região os mantenedores dos rebanhos mais importantes, totalizando $75,7 \%$ da produção brasileira: Rio Grande do Sul, 40,9\%; Santa Catarina, com 18,3\%; e Paraná, com 16,5\%. Em termos municipais, aparecem os municípios de Dois Irmãos (RS), Mogi das Cruzes (SP) e Santa Maria (RS) como os principais produtores de coelhos (IBGE, 2012).

Diante da problemática apresentada, desencadeia-se a necessidade pela busca de alternativas alimentares de origem cárnea que minimizem os impactos ambientais gerados já que a preocupação com atividades produtivas sustentáveis no âmbito do agronegócio é considerada emergente, portanto, atividades que melhorem a condição de vida das populações e conservem o meio ambiente estão no centro das discussões contemporâneas (SOUZA FILHO, 2012). Desse modo, o coelho, pela sua baixa necessidade relativa de investimentos e pelos impactos positivos de produção, apresenta-se como uma boa alternativa de produção sustentável.

O estudo em questão tem como objetivo principal apresentar subsídios necessários para tornar a produção da carne cunícula no Brasil uma alternativa 
sustentável, visto que a produção de coelhos ocupa pequenos espaços nas propriedades, ao contrário da produção de bovinos, suínos ou aves, com reduzida mão de obra e pequenos investimentos, além de permitir aproveitamento de praticamente todos os derivados da produção (pele, pelos, urina, entre outros).

Por meio de revisão bibliográfica, busca-se reconhecer as características da produção cunícula e suas particularidades, levantar informações quanto à produção da carne de coelho no Brasil e no mundo e destacar os pontos fortes e fracos, bem como as oportunidades e ameaças que a produção apresenta frente ao contexto da sustentabilidade.

\section{A SUSTENTABILIDADE E A AGRICULTURA SUSTENTÁVEL}

O tema sustentabilidade vem sendo amplamente discutido nas mais diversas esferas, dada a importância que representa para o desenvolvimento das nações. A sustentabilidade no contexto do desenvolvimento sustentável é definida por Brundtland (1987) como formas de progresso que atendam às necessidades do presente sem comprometer a capacidade de as gerações futuras satisfazerem as suas necessidades. Nesse sentido, com a difusão do termo sustentabilidade, o conceito do Triple Bottom Line (TBL), ou o tripé da sustentabilidade, passou a abranger os aspectos econômicos, social e ambiental, ganhando espaço no meio acadêmico e fazendo parte das estratégias das empresas como inovação e geração de valor (BRUNDTLAND, 1987).

Segundo Barbosa (2007), os componentes fundamentais para o desenvolvimento sustentável consistem em crescimento econômico, proteção ao meio ambiente e igualdade social. Esses fundamentos, aliados à mudança do paradigma das empresas, que tinham como único foco o lucro, passaram por uma concepção de desenvolvimento sustentável, dando origem ao TBL da Sustentabilidade, difundido por Elkington (1997).

A agricultura sustentável tem sido vagamente definida como "tecnologias e práticas agrícolas que maximizam a produtividade da terra, enquanto buscando minimizar os danos, tanto para ativos avaliados naturais (solos, água, ar e 
biodiversidade) e para a saúde humana (agricultores e outras pessoas rurais e consumidores)" (PRETTY, 2002, p. 171).

Desse modo, Gliessman (2014) considera as seguintes necessidades para a prática de uma agricultura mais sustentável: busca de melhorias no sistema, visando reduzir a utilização de insumos, busca pela utilização de insumos considerados mais sustentáveis, redesenho do sistema com base em princípios ecológicos e, por fim, restabelecimento de conexões entre produtores e consumidores para, assim, apoiar a transformação social e ecológica do sistema alimentar.

\subsection{A PRODUÇÃO CUNÍCULA}

A produção de coelhos se caracteriza pela elevada proliferação, com ninhadas que podem chegar, em condições ideais, a até 12 láparos ou mais por ninhada, podendo as fêmeas gestar até cinco ninhadas anuais (DJAGO; KPODEKON; LEBAS, 2007). Essa atividade é considerada uma das produções de carne com mais elevado rendimento produtivo e em ritmo intenso, visto que na fase de crescimento alcançam ganhos de peso médio de $40 \mathrm{~g}$ por dia, atingindo a idade de abate 40 dias após a desmama, quando se utilizam de dietas devidamente balanceadas, representando uma conversão alimentar comparável à do frango comercial (DE BLAS, 1984).

Já em aspectos de alimentação, os animais se alimentam de dietas com baixos teores de energia e ricos em fibra (LUKEFAHR, 1998). Os principais alimentos podem ser forragens, cascas de frutos, verduras e legumes, dentre outros. Nos sistemas de produção de coelhos de baixa escala, a utilização de recursos é limitada, aplicando-se alimentos nas explorações agrícolas da própria propriedade, materiais locais para a construção de gaiola, e mão de obra familiar (FINZI, 2000; LUKEFAHR, 2007). Nesse sistema, um ou dois coelhos são abatidos a cada semana para atender às necessidades da família e os coelhos ou carcaças são vendidos no mercado local, para gerar renda.

Por outro lado, o coelho para a produção em escala comercial é caracterizado por uma substancial iniciativa de investimentos, em estrutura física (prédio, instalações e equipamentos de enjaular), pela contínua quantidade de insumos (ração comercial e material genético híbrido) bem como recursos humanos. A 
produção é direcionada para os mercados urbanos e para a exportação (FINZI, 2000; LUKEFAHR, 2007).

\subsubsection{Consumo de carne de coelho no Brasil e no mundo}

A produção de coelhos no Brasil ainda se apresenta em fase de desenvolvimento. O país, segundo dados da FAO (2011), produz aproximadamente 1.575 t de carne de coelho, correspondentes ao $32^{\mathrm{a}}$ lugar em relação a outros países produtores. Para Machado (2012), o setor produtivo de coelhos no Brasil se encontra, de maneira geral, pouco organizado. Há a identificação de algumas iniciativas locais, que contemplam produtores, abatedouros, fábricas de ração, distribuição e aproveitamentos de produtos.

Quanto ao consumo da carne de coelho pelos brasileiros, conforme o IBGE (2010), ainda é pequeno, alcançando apenas $100 \mathrm{~g}$ per/capita ano, conforme representação gráfica a seguir.

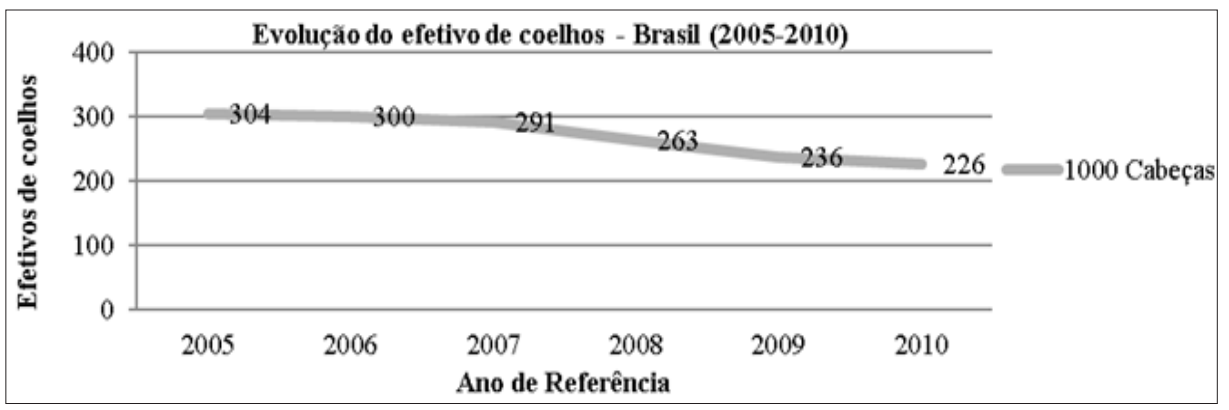

Gráfico 1. Evolução do efetivo de coelhos no Brasil de 2005 a 2010.

Fonte: Adaptado IBGE (2010).

Observa-se que a produção efetiva de coelhos diminuiu em aproximadamente 26\% (78 mil cabeças) de 2005 a 2010. No último período (2010), há queda de 4,2\% relativamente a 2009. Todas as grandes regiões brasileiras apresentaram queda no efetivo, Centro-Oeste (-13,5\%), Sul (-4,9\%), Nordeste $(-2,8 \%)$, Sudeste $(-1,5 \%)$ e no Norte $(-1,4 \%)$ (IBGE, 2010). O Censo revela que a cunicultura é praticada em estabelecimentos pequenos, sendo 45\% com área de até 10ha . Considerando-se a população desses animais, esses estabelecimentos respondem por $56 \%$ dos animais. 
Estudo realizado por Bonamigo (2014) na cadeia cunícula em Santa Catarina apresentou que há baixa frequência do consumo da carne de coelho, sendo situações de consumo em finais de semana, festas, churrascarias e restaurantes, esse fator está relacionado ao acesso do produto pelo consumidor, que acontece normalmente por conveniência diretamente dos produtores para os consumidores finais ou por amigos e conhecidos.

Porém ainda são vários os principais entraves para o consumo da carne de coelho no Brasil, os quais estão diretamente relacionados aos hábitos de consumo do brasileiro além do desconhecimento do consumidor quanto aos benefícios nutricionais da carne de coelho. Para Ferreira et al. (2010), a carne de coelho ainda é pouco difundida, refletindo principalmente a falta de tradição na produção e consumo, já que muitos consideram o coelho apenas animal de estimação, também há falta de incentivos governamentais à pesquisa e ausência de abatedouros especializados oficiais. Para Vieira (2008), o consumo de carne de coelho pelos brasileiros não é uma prática comum, considerando-se que não se difundiu pela falta de oferta da já considerada iguaria e, sobretudo, pela falta de organização do setor, que não estimula o consumo tampouco divulga as qualidades e benefícios da carne. Há, portanto, a necessidade de se criar esforços no sentido de o consumidor brasileiro receber mais informações e esclarecimentos quanto aos benefícios nutricionais da carne cunícula.

De acordo com Carvalho (2009), a quantificação da produção cunícula mundial é tarefa complicada e delicada de lograr. Os valores nacionais são escassos ou não existem em alguns países e em outros estão agrupados com a produção de outras espécies. Existe uma cota muito elevada de autoconsumo que é difícil de quantificar e na maioria dos países não existe um sistema de recenseamento das explorações que permita a compilação de informação. Desse modo, deve-se ser cauteloso na análise dos valores apresentados na bibliografia e não se esquecer de que em certos países os valores são obtidos por estimativa.

Segundo a FAOSTAT (Nações Unidas para Alimentação e Agricultura) (2014), o efetivo mundial de coelhos apresentou variações de forma alternada, sendo que em 2002 o efetivo mundial foi de 592.918,3 cabeças, já em 2012 apresentou um crescimento de 35,42\% $(918.218,48)$ (Figura 2). 


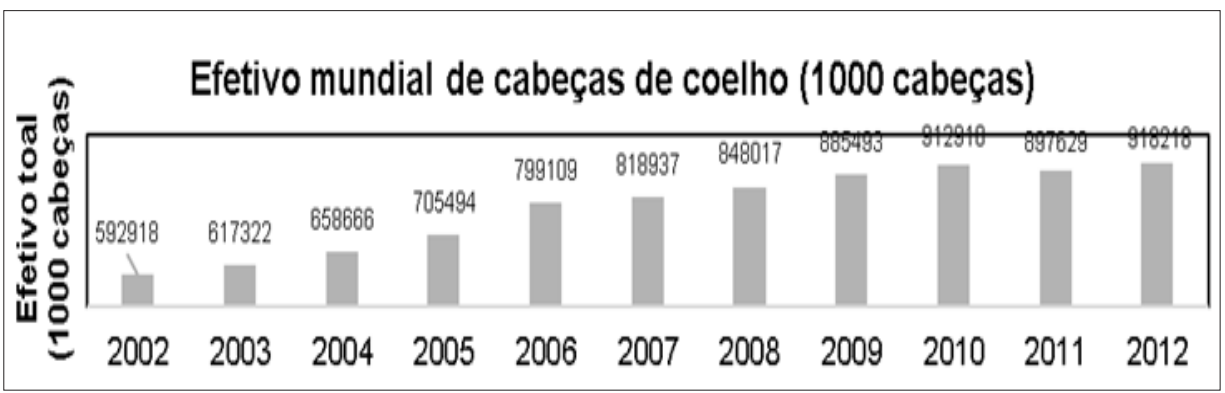

Gráfico 2. Efetivo mundial de cabeças no período.

Fonte: Adaptado FAOSTAT (2014).

É possível verificar um déficit no período de 2010 para 2011 de 912.917,64 mil cabeças para 897.629,11 mil cabeças (-1,6\%) e em 2012 um aumento acima do efetivo comparado a 2010, 918.218,48 mil cabeças (Figura 3).

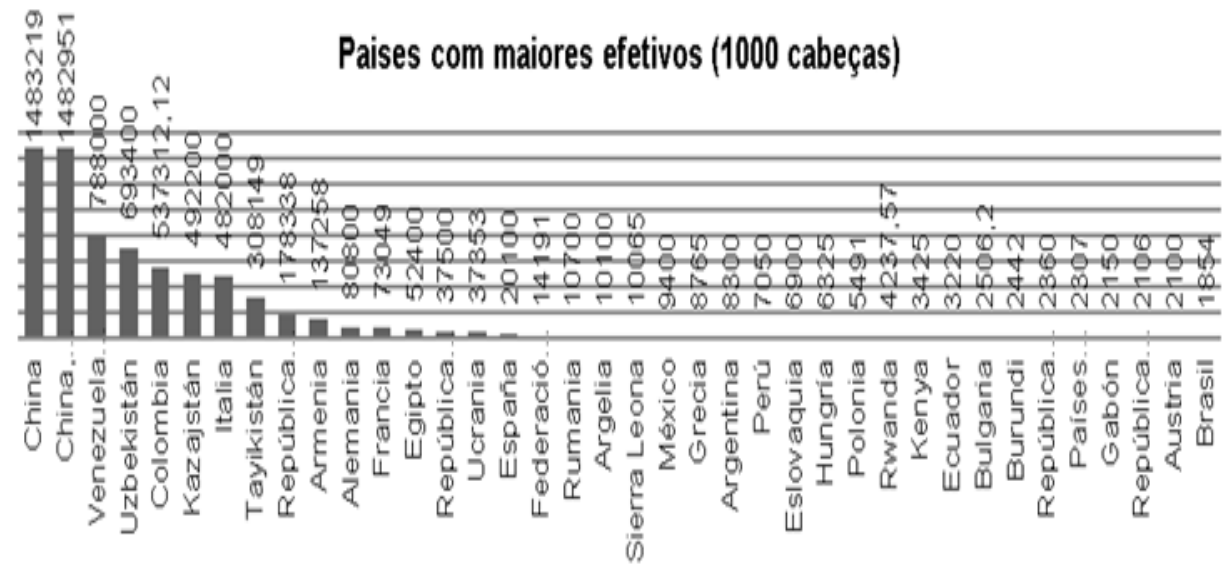

Gráfico 3. Países com maiores efetivos cunículas (1.000 cabeças).

Fonte: Adaptado FAOSTAT (2013)

A China, além de possuir a maior população de coelhos, também é considerada o maior produtor de carne de coelho mundial. De acordo com a FAO (2011), a China produz cerca de $685.000 \mathrm{t}$ de carne de coelho, seguida da Venezuela, a qual produz $270.000 \mathrm{t}$.

Portanto, a China é o primeiro país no ranking mundial em quantidade de 
coelhos criados e do output de produtos, bem como em termos de pelo e carne de coelho exportados (HANPING et al., 2002). A cunicultura chinesa tem como principal atividade a produção de pelo/lã Angorá. Segundo Colin (1995), esta representa um valor 2,5 vezes superior ao da carne, sendo essa considerada um subproduto. Uma grande percentagem da carne produzida provém do abate de jovens coelhos Angorá. O número desses coelhos era superior aos 63 milhões, em 1994, e havia 0,9 milhão de coelhos (ZHANG et al., 1996).

\subsection{A PRODUÇÃO CUNÍCULA COMO ALTERNATIVA SUSTENTÁVEL}

A busca por produtos alternativos demandou nos últimos anos intensos estudos de forma a desenvolver novos produtos complementares ou mesmo substitutos dos tradicionais de forma a suprir as crescentes demandas por alimentos cárneos e por condições de readequações de hábitos alimentares, saúde e bem-estar. Nesse sentido, a carne de coelho é considerada uma carne magra e saudável em relação às carnes bovina, ovina e suína, sendo também mais digestível, saborosa e de poucas calorias (HERNÁNDEZ et al., 2000).

Gonzáles (2006) caracteriza a carne de coelho pela baixa taxa de gorduras, colesterol e proteínas e elevado nível de ferro. Considera-se também uma fonte de vitaminas do complexo B (B2, B3, B5, B12) (COMBES, 2004). Em uma criação eficiente, coelhos convertem até $20 \%$ da proteína consumida em carne, mais do que os suínos (15-18\%) e bovinos (9-12 \%) (SUTTLE, 2010). Na questão de conteúdo de cálcio e fósforo, estes são mais elevados do que em outros tipos de carne, bem como o ácido nicotínico (13 mg / $\mathrm{kg}$ de carne) (WILLIAMS, 2007). Além disso, a carne de coelho não contém ácido úrico e tem baixo teor de purinas (HERNÁNDEZ et al., 2007).

Além da carne, os miúdos (vísceras comestíveis) dos coelhos apresentam procura no mercado, a pele é demandada pela indústria de roupas, o couro é utilizado para substituir a camurça na produção de luvas, bolsas e calçados. As vísceras podem ser utilizadas na fabricação de farinha, e o esterco pode ser empregado em plantações como adubo (DOS ANJOS et al., 2014).

Velazquez et al. (1998) informam que os produtos finais devem ter suas propriedades intrínsecas e extrínsecas identificadas, sejam propriedades físicas, químicas e atributos especiais, como produtos saudáveis, ecologicamente corretos, com propriedades nutricionais específicas. Para dietas, a carne contribui para uma 
quantidade significativa de cálcio, fósforo e vitaminas, sendo recomendada para crianças, idosos e especialmente para aqueles com colesterol elevado, risco de aterosclerose e doenças cardiovasculares (LEBAS; OUHAYOUN, 1993) e um produto alimentar saudável, de fácil digestão (DALLE ZOTTE, 2000).

\subsubsection{A produção cunícula e o impacto ambiental}

Quanto aos impactos ambientais, sabe-se que essa questão está sendo amplamente discutida, ainda mais quando se está em evidência o manejo dos recursos naturais. Nesse sentido, o quadro a seguir destaca as características e consequências ambientais da produção cunícula.

Quadro 1. Caracterização da produção cunícula

\begin{tabular}{|c|c|}
\hline Fator & Descrição \\
\hline Espaço & Baixa necessidade de área útil para produção e manejo \\
\hline Trabalho leve & Considerada manejo com baixo esforço físico \\
\hline $\begin{array}{l}\text { Proliferação da } \\
\text { espécie }\end{array}$ & Os animais podem ser produzidos no próprio estabelecimento \\
\hline Alimentação & Aproveitamento de alimentos de baixo valor nutricional \\
\hline Resíduos gerados & $\begin{array}{l}\text { Geração de esterco de alta qualidade, considerado um excelente adubo } \\
\text { orgânico. Em sistemas sustentáveis, o resíduo de um passa a ser insumo } \\
\text { de outro sistema produtivo. }\end{array}$ \\
\hline Consumo de água & $\begin{array}{c}\text { Baixa necessidade de água - a água utilizada é praticamente destinada à } \\
\text { bebida dos animais. }\end{array}$ \\
\hline Miúdos do animal & Possibilidade do aproveitamento de subprodutos do abate \\
\hline
\end{tabular}

Fonte: Adaptado ACBC (2011).

Como se pode identificar, há vários fatores que favorecem a produção cunícula, uma delas refere-se à área útil para produção e manejo, a qual é considerada baixa, diferentemente de outros animais que requerem maior espaço para criação. O trabalho também é considerado leve, comparativamente com outras produções, a exemplo de suínos e gado, requerendo baixo esforço físico. Há também a proliferação da espécie no próprio espaço além da possibilidade de se realizar o aproveitamento alimentar, considerado de baixo valor nutricional. Destaca-se ainda 
que a produção cunícula gera resíduos de alta qualidade e há baixa necessidade do consumo de água, destinando-se quase que sua totalidade apenas ao consumo dos animais. Além de todos os benefícios apontados, todos os miúdos do coelho podem ser aproveitados, dificilmente sendo desperdiçados.

Desse modo, a produção cunícula apresenta características favoráveis em aspectos econômicos e para a oferta de alimentos de forma sustentável, diante da baixa demanda de espeço para o manejo dos animais, elevada proliferação da espécie, baixa utilização de água, características alimentares da carne e possibilidade de agregação de valor dos subprodutos gerados, como miúdos e pele.

\subsubsection{A produção cunícula como alternativa econômica}

Conforme já apresentado, a produção e comercialização de coelho podem ser realizadas em diversificadas escalas. De acordo com a ACBC (Associação Científica Brasileira de Cunicultura), o coelho pode ser vendido, vivo, para alguns mercados, abatido (carne) ou para a venda da pele e pelo (Quadro 2).

Quadro 2. Média de preços praticados - coelhos no Brasil5 (Continua)

\begin{tabular}{|c|c|c|c|c|c|}
\hline Item & & $\underset{(\mathrm{R} \$)}{\text { Mínimo }}$ & $\begin{array}{l}\text { Máximo } \\
(\mathrm{R} \$)\end{array}$ & $\begin{array}{l}\text { Médio } \\
(\mathrm{R} \$)\end{array}$ & $\begin{array}{l}\text { Sugerido } \\
\text { (R\$) }\end{array}$ \\
\hline \multicolumn{6}{|l|}{ Venda de animais vivos } \\
\hline Coelhos vivos para abate & $\mathrm{Kg}$ & 4,50 & 5,50 & 4,90 & - \\
\hline $\begin{array}{l}\text { Coelhos vivos sem raça definida (SRD) para } \\
\text { revenda em casas agropecuárias }\end{array}$ & Um & - & - & - & 5,00 \\
\hline $\begin{array}{l}\text { Coelhos vivos de raça anã comercializados para } \\
\text { casa agropecuária ou Pet Shop** }\end{array}$ & $\mathrm{Um}$ & - & - & - & 20,00 \\
\hline $\begin{array}{l}\text { Animais SRD ou Nova Zelândia Branco (NZB) } \\
\text { vivos vendidos separadamente }\end{array}$ & $\mathrm{Um}$ & 8,00 & 50,00 & - & - \\
\hline $\begin{array}{l}\text { Animais de raças definidas vendidos } \\
\text { separadamente** }\end{array}$ & $\mathrm{Um}$ & - & - & - & - \\
\hline Venda de carne e produtos cárneos & & & & & \\
\hline
\end{tabular}

5 Cotação apresenta pela ACBC (2011). 
(Conclusão)

\begin{tabular}{|c|c|c|c|c|c|}
\hline Item & & $\begin{array}{l}\text { Mínimo } \\
(\mathrm{R} \$)\end{array}$ & $\begin{array}{l}\text { Máximo } \\
(\mathrm{R} \$)\end{array}$ & $\begin{array}{c}\text { Médio } \\
(\mathrm{R} \$)\end{array}$ & $\begin{array}{c}\text { Sugerido } \\
\text { (R\$) }\end{array}$ \\
\hline Carne de coelho inteiro & $\mathrm{Kg}$ & 8,00 & 24,00 & 14,40 & - \\
\hline Carne de coelho desossado & $\mathrm{Kg}$ & - & - & - & 40,00 \\
\hline Molho de coelho para pizza & $\mathrm{Kg}$ & - & - & - & 20,00 \\
\hline Patê de coelho & $\mathrm{Kg}$ & - & - & - & 35,00 \\
\hline \multicolumn{6}{|l|}{ Venda de peles e pelos } \\
\hline Peles frescas sem curtimento & $\mathrm{Um}$ & 1,00 & 3,00 & 2,25 & - \\
\hline Peles curtidas & $\mathrm{Um}$ & 5,00 & 30,00 & 15,80 & - \\
\hline Pelos & $\mathrm{Kg}$ & - & - & - & 100,00 \\
\hline \multicolumn{6}{|l|}{ Outros Subprodutos } \\
\hline Patas frescas & $\mathrm{Um}$ & 0,20 & 2,00 & - & - \\
\hline Patas vendidas como chaveiros & $\mathrm{Um}$ & - & - & - & 3,00 \\
\hline Rabo & Um & - & - & - & 2,50 \\
\hline Esterco curtido & $\mathrm{Kg}$ & 0,40 & 2,00 & - & - \\
\hline Esterco curtido & $\mathrm{m}^{3}$ & - & - & - & 150,00 \\
\hline Sangue & Lt & 100,00 & 130,00 & - & - \\
\hline Orelha & $\begin{array}{c}\text { Pc com } \\
10\end{array}$ & $\cdot$ & $\cdot$ & $\cdot$ & $\begin{array}{c}2,50 \mathrm{a} \\
5,00\end{array}$ \\
\hline Vísceras & $\mathrm{Um}$ & - & - & - & 0,50 \\
\hline Cérebro & $\mathrm{Kg}$ & 50,00 & 100,00 & - & - \\
\hline Olhos & $\mathrm{Um}$ & - & - & - & 2,00 \\
\hline Bexiga cheia (urina) & $\mathrm{Um}$ & - & - & - & 0,25 \\
\hline
\end{tabular}

*Para determinação do preço médio, pelo menos quatro observações foram utilizadas. Quando não se obteve esse número, o valor é apenas sugerido. **Pode variar conforme a raça do animal. Fonte: ACBC (2011). 
Para a comercialização, o animal vivo pode ser destinado a abatedouros, seu valor varia na média de $\mathrm{R} \$ 5,00 / \mathrm{kg}^{6}$ (de coelho vivo). Além disso, pode ser vendido em casas agropecuárias como pet.

Quanto à sua carne, o coelho pode ser vendido inteiro, com o valor médio de $\mathrm{R} \$ 14,40 / \mathrm{kg}$, dependendo da região. Já outros subprodutos podem ser comercializados com base na carne de coelho, o que acaba agregando valor ao produto, podendo ser comercializada a carne desossada, cujo valor poderá variar até $\mathrm{R} \$ 40,00 / \mathrm{kg}$, além de outros produtos a exemplo de patês (a partir do fígado) que pode chegar a $\mathrm{R} \$ 35,00 / \mathrm{kg}$.

As peles poderão ser comercializadas frescas ou já curtidas (beneficiadas). No primeiro caso, o valor pode chegar a $\mathrm{R} \$ 5,00 \mathrm{e}$, para as peles curtidas, dependerá da qualidade do processamento, podendo chegar a $\mathrm{R} \$ 30,00$. Quanto aos pelos, o $\mathrm{kg}$ de lã de boa qualidade pode chegar a $\mathrm{R} \$ 100,00$. Além desses produtos, comercializam-se do coelho patas (para chaveiros), rabo, esterco curtido, sangue, orelha, vísceras, cérebro (para laboratórios), bexiga e olhos.

Os dados apresentados demonstram a precificação das peças do coelho no mercado brasileiro, verifica-se variação de preços e que às diversas partes do animal é possível agregar valor, ou seja, é possível gerar renda. A precificação do coelho para a comercialização no Brasil, em função de seu baixo desenvolvimento, não é definida por órgãos públicos ou privados, diferente da UE (União Europeia), onde o preço do coelho pago ao produtor é fixado semanalmente pela Bolsa Ibérica. $\mathrm{O}$ mercado português tem por base os valores estipulados nesta bolsa, valor que é determinado com base na produção e transformação (PAC, 2013).

\subsubsection{Produção cunícula como elemento para o desenvolvimento social}

As transformações nas bases da agricultura e na migração de um modelo tradicional para um modelo sustentável passam pela transformação da sociedade, assim, não é uma simples substituição de implementos que fortalecerão as novas práticas, mas a promoção de políticas públicas, voltadas para o fortalecimento dessa agricultura (MOREIRA; CARMO, 2004).

6 Cotação apresentada pela ACBC (2011). 
Desse modo, ao se voltar à produção cunícula como propulsora para o desenvolvimento social, pode-se associá-la a uma alternativa para a agricultura familiar, que em muitos momentos está relacionada ao desenvolvimento sustentável. Assim, de acordo com Soares, Melo e Chaves (2009), a agricultura familiar corresponde a uma unidade de produção agrícola, em que propriedade e trabalho estão intimamente ligados à família, ou seja, têm duas características principais, administração e trabalho familiar. Quanto ao fato de a agricultura familiar estar vinculada ao desenvolvimento sustentável, Teodoro et al. (2005) argumentam que, a partir do momento em que o êxodo rural se torna um problema para os centros urbanos, percebe-se a necessidade de incentivo para a agricultura familiar como forma alternativa de desenvolvimento.

Ainda de acordo com os autores, o incentivo à permanência da população rural no campo torna-se cada vez mais necessário, e a agricultura familiar passa a ser um importante fator de geração de renda e empregos para os pequenos agricultores, os quais não possuem muitas oportunidades. De acordo com Wanderley (2002), hoje a o meio rural aparece também como portador de soluções, vinculado à melhoria do emprego e da qualidade de vida que proporciona.

Portanto, verifica-se que a produção de coelhos se justifica não apenas por sua carne, mas a pele e todo o aproveitamento animal que podem ser utilizados como alternativas de geração de renda para uma organização. Talvez o pequeno produtor ainda não consiga fazer essa otimização com a produção em pequena escala. Tornase necessário, assim, estruturar a cadeia de produção, criar associações, cooperativas ou entidades de suporte que possam fomentar o desenvolvimento de subnegócios derivados da expansão da atividade cunícula.

\section{PROCEDIMENTOS METODOLÓGICOS}

$\mathrm{O}$ presente artigo caracteriza-se pela pesquisa qualitativa e descritiva. De acordo com Gil (1999, p. 46), na pesquisa descritiva, o objetivo primordial é a descrição das características de determinada população ou fenômeno ou, então, o estabelecimento de relações entre as variáveis. Torna-se adequado classificar o estudo como descritivo, pelas descrições das caracterizações do sistema de produção cunícula em relação às abordagens básicas da sustentabilidade e também na aplicação do agronegócio. 
A pesquisa estrutura-se em dados e informações por meio de estudos bibliográficos sobre a temática do estudo, sejam eles revistas, artigos, sites e livros relacionados ao tema, utilizando-se de dados secundários. A metodologia estrutura-se por etapas tradicionais: identificação, localização, compilação, análise e interpretação das informações (LAKATOS; MARCONI, 1986).

No estudo, utilizou-se como base a Revisão Bibliográfica Sistemática Road Map, proposta por Conforto e Amaral (2011), para se encontrar subsídios necessários para contribuir para a produção da carne cunícula no Brasil se tornar uma alternativa sustentável.

$\mathrm{Na}$ primeira etapa, foi realizada uma pesquisa exploratória em livros e sites relacionados ao sistema agroindustrial com o objetivo de encontrar fatores considerados influenciadores na busca de alternativas sustentáveis e maior interação com o tema.

A segunda etapa buscou identificar artigos em revistas acadêmicas e anais largamente conhecidos no meio acadêmico e na área da cunicultura. A busca foi realizada eletronicamente através do site da Associação Científica Brasileira de Cunicultura e em base de dados como a ProQuest, B-On, periódicos da Capes, Scielo, Scopus, ISI Web of Science e Ebsco. Para se encontrar os artigos de interesse, restringiu-se a busca através das palavras-chave rabbit, sustainable alternative, sustainability. Utilizaram-se operadores booleanos como "AND", "OR" e "NOT". Limitou-se a trabalhos publicados nos últimos 15 anos.

Em seguida, realizou-se a leitura nos resumos dos artigos, em que se buscou verificar se o artigo apresentava relação com o objetivo do estudo. Desse modo, caso no resumo não constasse o assunto, o artigo era consequentemente desconsiderado. A partir dessa análise, identificou-se uma pequena quantidade de artigos que tratavam especificamente do assunto em questão (considerado uma das limitações da pesquisa).

A terceira etapa procurou analisar os documentos relacionados à cunicultura como alternativa sustentável no Brasil. A justificativa foi escolhida por meio da interpretação de passagens do texto, sendo escolhida a mais representativa para a cunicultura como alternativa sustentável brasileira. Em seguida, procedeu-se a análise desses fatores.

Na última etapa o estudo integrou-se a uma revisão bibliográfica por meio de dados secundários, relacionados à produção cunícula no Brasil e no mundo, em seguida foram associados com os aspectos da sustentabilidade de forma a propor 
uma posição por meio da análise SWOT da atividade cunícula como alternativa sustentável no Brasil.

Segundo Mcdonald (2004), a análise de SWOT é definida como um resumo $\mathrm{da}$ auditoria sob os títulos forças e fraquezas relacionadas às oportunidades e ameaças externas. Isso corresponde dizer que é efetuada uma análise minuciosa a fim de se identificar os pontos fortes e fracos, com o intuito de trabalhá-los da melhor maneira possível.

\section{RESULTADO E DISCUSSÃO}

Após análise dos dados, podem-se identificar os fatores internos, subdivididos em forças e fraquezas, e as variáveis externas, subdivididas em oportunidades e ameaças quanto ao desenvolvimento da atividade cunícula, representado a partir da análise SWOT na figura a seguir:
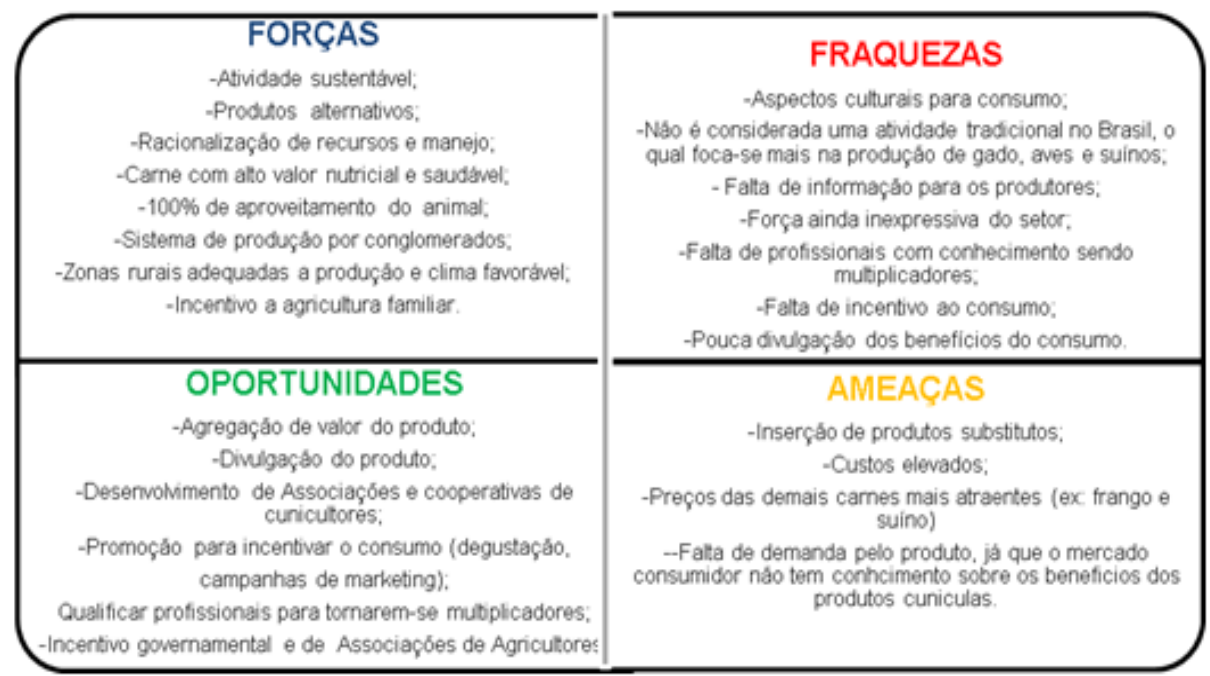

Figura 1. Fatores de influência para o desenvolvimento da atividade cunícula. (na figura, em Ameaças, corrigir a palavra conhecimento)

Conforme apresentação da matriz SWOT, percebe-se que as forças existentes para a produção da carne de coelho podem representar uma alternativa favorável 
para quem deseja trabalhar com um produto sustentável, tanto no âmbito comercial, mediante os resultados econômicos que pode promover, como nas consequências de ordem ambiental. Certamente, o fato de ser uma atividade sustentável representa ganhos significativos tanto para o produtor quanto para o meio ambiente, pois a produção cunícula representa um produto alternativo, podendo significar uma oportunidade para quem deseja investir nesse negócio.

Outros aspectos que fortalecem o segmento são a racionalização de recursos e o manejo assim como as particularidades do consumo dessa carne, que é caracterizada pelo alto valor nutricional e pelo apelo saudável que proporciona aos consumidores, contribuindo para uma quantidade significativa de cálcio, fósforo e vitaminas em especial, para crianças, idosos e pessoas com problemas de colesterol elevado, risco de aterosclerose e doenças cardiovasculares, já apostadas por Lebas e Ouhayoun (1993). Além disso, é considerado um produto alimentar saudável e de fácil digestão.

Em relação à produção no Brasil, considera-se também como um aspecto positivo o fato de o país possuir algumas regiões com zonas rurais adequadas à produção e o clima favorável. Também há de se mencionar o incentivo à agricultura familiar, promovendo a empregabilidade e gerando renda para as famílias que optarem por essa atividade.

Já em relação às principais fraquezas identificadas, mencionam-se inicialmente os aspectos culturais para consumo, o que pode ocasionar baixa procura, pois muitos acabam não consumindo por questões tradicionais, conforme já levantado. Ainda o fato de o consumidor relacionar o coelho a eventos festivos (coelho da Páscoa) ou como animal de estimação acaba por criar limitação ao consumo da espécie.

Por parte dos produtores, a organização do trabalho e o desenvolvimento de relações para assegurar volume de venda de animais, sistematizando sua atividade em relação ao mercado e aplicação de novas tecnologias de produção como inseminações e ferramentas de gestão da atividade, são fatores que demandam melhorias (BONAMIGO, 2015).

Percebe-se também que a produção cunícula não é considerada uma atividade tradicional no Brasil, já que o país se foca mais na produção de gado, aves e 
suínos, tornando-se necessária a promoção de políticas públicas de forma a promover o consumo e produção da espécie. A formação de associações e cooperativas entre produtores é uma alternativa para promoção, pois, além de posicionamento no mercado, favorece a disseminação de tecnologias produtivas.

Além do social, gerando renda, empregabilidade e sustentabilidade financeira para as famílias, a produção cunícula pode tornar-se uma alternativa para a agricultura familiar. No âmbito ambiental, os ganhos são inúmeros, vistos os vários aspectos quanto ao baixo impacto ambiental que a produção cunícula promove.

Há de se mencionar que, dentre as fraquezas e ameaças encontradas, para os atores da atividade é importante adotar medidas, visando-se neutralizar aquelas. Desse modo, estratégias visando ao fortalecimento do consumo do produto, instigado pela promoção e campanhas de divulgação, certamente implicarão em um resultado mais favorável, pois ainda há barreiras de ordem cultural em algumas regiões brasileiras, o que necessita ser trabalhado. Estabelecer parcerias estratégicas pode ser uma alternativa interessante, principalmente com entidades a exemplo do SEBRAE - Serviço Brasileiro de Apoio à Micro e Pequena Empresa, o qual dispõe de programas e projetos para incentivar e propagar o consumo de alguns produtos.

O sistema atual de fixação de preços demonstra desunião do setor produtor que leva a uma maior debilidade deste em relação ao valor de comercialização. Esse fator se apresenta diante do fato de que cada cunicultor negocia individualmente o preço com o abatedouro, ocorrendo diferenciações de preços entre os diversos produtores, e esse fator promove maior união e cooperação entre os atores, podendo promover a atividade no Brasil.

Para a cooperação, é fundamental que o produtor efetue alianças entre elos da cadeia de produção, integração entre produtores por sistemas de cooperação e associativismo de forma a fortalecer a vantagem competitiva no mercado e a promoção da carne cunícula no mercado brasileiro.

\section{CONSIDERAÇÕES FINAIS}

Com base no estudo realizado, percebe-se que a carne cunícula representa, na atualidade, uma alternativa para promover a sustentabilidade na área rural. Pode-se constatar a necessidade de se realizar outros estudos, para se identificar as 
barreiras de produção bem como o consumo da carne de coelho no Brasil, visandose, assim, contribuir para a sustentabilidade do setor cunícula no país.

Identificou-se que há demanda pela estruturação da cadeia de produção, incluindo fornecedores de insumos, indústrias processadoras, órgãos de pesquisa, assistência técnica, fornecedores de máquinas, equipamentos, embalagens, mapeamento de mercado (supermercados, mercearias, quitandas e feiras-livres) e intensificação da divulgação (a exemplo de food service e refeições para a aviação comercial, hospitais e escolas).

O estudo realizado apontou limitações em relação à coleta de dados no que tange à produção brasileira. Outra limitação importante considerada foi a reduzida quantidade de material científico publicado, relacionado à cunicultura brasileira e seus atores e permitindo afirmar que a área cunícula precisa ser amplamente estudada.

\section{REFERÊNCIAS}

ACBC - Associação Científica Brasileira de Cunicultura. A cunicultura e o Desenvolvimento Sustentável. Disponível em: <http://www.acbc.org.br $>$. Acesso em: 16 abr. 2014.

BARBOSA, P. R. A. Índice de sustentabilidade empresarial da bolsa de valores de São Paulo (ISE-BOVESPA): exame da adequação como referência para aperfeiçoamento da gestão sustentável das empresas e para formação de carteiras de investimento orientadas por princípios de sustentabilidade corporativa. 2007. Dissertação (Mestrado em Administração) - Universidade Federal do Rio de Janeiro - UFRJ, Instituto COPPEAD de Administração, 2007.

BRASIL. Ministério da Agricultura Pecuária e Abastecimento. Exportação. Disponível em: < http://www.agricultura.gov.br/animal/exportacao > . Acesso em: 15 abr. 2014.

BRUNDTLAND, G. H. Our common future: the world commission on environment and development. Oxford: Oxford University Press, 1987. 
CARRANZA, J. Método de planificación del desarrollo tecnológico em cadenas agroindustriales que integran princípios de sostenibilidad y competitividad. La Haya, ISNAR, 1998.

CARVALHO, R. C. Caracterização da produção cunícula nas regiões De Trás-osMontes, Minho e Galiza. Vila Real. Dissertação apresentada na Universidade de Tras-os-Montes e Alto Douro. 2009. 139p.

COLIN, M. La conigliocoltura nei paese dela CEE. Rivista di conigliocoltura, Bologna, v. 29, n. 12, p.13-22, 1992.

COMBES S. Valeurnutritionnelle de la viande de lapin. Prod. Anim., v. 17, p. 373$383,2004$.

CONFORTO, E. C., AMARAL, D. C., SILVA, S. L. D. Roteiro para revisão bibliográfica sistemática: aplicação no desenvolvimento de produtos e gerenciamento de projetos. In: Anais Congresso Brasileiro de Gestão de Desenvolvimento de Produtos, 2011.

DALLE ZOTTE A. Main factors influencing the rabbit carcass and meat quality. In: PROCEEDINGS OF THE 7TH WORLD RABBIT CONGRESS, 2000. Proceedings... Valencia, Spain: [s.n.], 2000. p. 1-32.

DJAGO, Y. A.; KPODEKON, M.; LEBAS, F. Méthodes et techniques d'Élevage du lapin. Elevageen milieu tropical. Cuniculture.info, 2007.

DOS ANJOS QUEIROZ, C. R. A., ANDRADE, R. R., DE LACERDA, Z. C., FERREIRA, M. E. Esterco de coelho: fonte de nutrientes para complementação da adubação. Revista Agrogeoambiental, v. 6, n. 3, 2014.

ELKINGTON, J. Cannibals with forks: the triple bottom line of $21^{\text {st }}$ century business. Oxford: Capstone, 1997.

FAO - Food and Agriculture Organization of the United Nations. FAOSTAT Agriculture data. Disponível em: < http:/faostat.fao.org/faostat/ collections?version $=$ ext\&hasbulk $=0 \&$ subset $=$ agriculture $>$. Acesso em: 25 fev . 
2014.

FAO - Food and Agriculture Organization of the United Nations. Aumenta as emissões de gases de efeito estufa da agricultura. Disponível em: $<$ https://www. fao.org.br/aegeea.asp > . Acesso em: 06 mar. 2016.

FAO - Food and Agriculture Organization of the United Nations. Livestock impacts on the environment. Disponível em: < http://www.fao.org/ag/magazine/0612sp1. htm >. Acesso em: 15 abr. 2014.

FAO - Food and Agriculture Organization of the United Nations. Tackling climate change through livestock: A global assessment of emissions and mitigation opportunities. Disponível em: < http://www.fao.org/docrep/018/i3437e/i3437e.pdf >. Acesso em: 06 mar. 2016.

FERREIRA, W. M. The rabbit Production in Brazil. In: RABBIT CONGRESS OF THE AMERICAS, 4., 2010, Córdoba. Proceedings... Córdoba: American Branch of the World Rabbit Science Association, 2010. p. 1-8.

FINZI, A. Raising rabbits for food security. In: WORLD RABBIT CONGRESS, 7., 2010, Valencia. Proceedings... Valencia: World Rabbit Science Association, 2000. p. 13-38.

GIL, A. C. Métodos e técnicas de pesquisa social. São Paulo: Atlas, 1999.

GONZÁLEZ-REDONDO P. Proposal of a nest box for the reproduction of wild rabbits (Oryctolagus cuniculus) in cages. World rabbit Sci 14, 115-121, 2006.

HERNÁNDEZ, P.; ALIAGA, S.; PLA, M.; BLASCO, A. Relationships between meat quality measurements in rabbits fed with three diets of different fat type and content. Meat Science, Barking, v. 55, n. 4, p. 379-384, 2000. Disponível em: < http://dx.doi. org/10.1207/S15327736ME1403_3>. Acesso em: 05 jun. 2014.

HERNÁNDEZ, P.; ALIAGA, S.; PLA, M.; BLASCO, A. The effect of selection for growth rate and slaughter age on carcass composition and meat quality traits in rabbits. Journal of Animal Science, Champaign, v. 82, n. 11, p. 3138-3143, 2004.

IBGE - Instituto Brasileiro de Geografia e Estatística. Censos. 2012. Disponível 
em: $\quad<$ http://www.ibge.gov.br/home/estatistica/indicadores/agropecuaria/ producaoagropecuaria/> . Acesso em: 01 de jun. 2013.

IBGE - Instituto Brasileiro de Geografia e Estatística. Produção da Pecuária Municipal. Disponível em: <http://www.ibge.gov.br/home/estatistica/economia/ ppm/2010/ppm2010.pdf> . Acesso em: 29 de out. 2013.

IBGE - Instituto Brasileiro de Geografia e Estatística, 2010. Cidades. Disponível em: <www.ibge.gov.br/cidadesat/topwindow.htm?1> Acesso em: 10 mar. 2014.

ICEA. Instituto Campineiro de Ensino Agrícola, 1969.

LAKATOS, E. M.; MARCONI, M. A. Fundamentos de metodologia científica. São Paulo: Atlas, 1986. 238p.

LEBAS, F. Y.; OUHAYOUN, J. Influência de la alimentación sobre la calidad de la carne de conejo: características organolépticas y presentación de La canal. Boletín de cunicultura, v. 16, n. 70, p. 16-20, 1993.

LEBAS, F.; COLIN, M. Production et consommation de viande de lapindansle monde estimationenl'an 2000. In: JORNADAS INTERNACIONAIS DE CUNICULTURA, 1., 2000. Anais... Vila Real, Portugal: [s.n.], 2000. p. 3-12.

LUKEFAHR, S. D. Rabbit production in Uganda: Potential versus opportunity. World Rabbit Science, v. 6, n. 3-4, p. 331-340, 1998.

LUKEFAHR, S. D. The Small - Scale Production model: Intermediate Factors. In: RABBITS CONGRESS OF THE AMERICAS, 3rd., 2007, Maringá City - Paraná State Brazil. 2007. (CD ROM).

MACHADO L. C. Opinião: Panorama da Cunicultura Brasileira. Revista Brasileira de Cunicultura, v. 2, n. 1, 2012.

MCDONALD, M. Plano de Marketing: Planejamento e Gestão estratégica: como criar e implementar. Rio de Janeiro: Elsevier, 2004. 
MOREIRA, R.M.; CARMO, M.S. Agroecologia na Construção do Desenvolvimento Rural Sustentável. Agric. São Paulo, v. 51, n. 2, p. 37-59, jul/dez. 2004.

PAC - Programa Agricultura Comum. Lisboa. Disponível em: < http://www.aspoc. pt/attachments/article/191/Cunicultura\%20-\%20PAC\%202013.pdf>. Acesso em: 25 fev. 2014.

PERLAS, N. The seven dimensions of sustainable agriculture. In: SHIVA, V. ; MOSHER. (Ed.). Biopolitics. London \& New Jersey: Zed Books, 1995. p. 234-266.

PORTAL ADMINISTRADORES. Análise SWOT (Matriz): Conceito e Aplicação. Disponível em: <http://www.portal-administracao.com/2014/01/analise-swotconceito-e-aplicacao.html > . Acesso em: 25 fev. 2014.

PRETTY, J. Agriculture: reconnecting people, land and nature. Earthscan; London, UK: 2002. p. 261.

SANTOS, F. B. Cunicultura: análise de viabilidade de gerar uma empresa voltada para criação de 500 coelhos por mês em Feira de Santana, Bahia. 2010. 93f. Monografia (Bacharel em Administração) - Universidade Estadual de Feira de Santana, Feira de Santana, BA.

SCHALLER, N. Sustainable agriculture and the environment: the concepto agricultural sustainability. Agriculture, Ecosystems and Environment, v. 46, p. 89-97, 1993.

SOUZA FILHO, H. M. Desenvolvimento agrícola sustentável. In: BATALHA, M. O. (Coord.). Gestão Agroindustrial: GEPAI: Grupo de Estudos e pesquisas Agroindustriais. 2. ed. São Paulo: Atlas, 2012, v. 1, p. 585-627.

SUTTLE, N.F. Mineral Nutrition of Livestock. $4^{\text {th }}$ ed. CAB International, Oxfordshire, UK, 2010.

TEODORO, P. A. V. B.; NAZZARI, R. K.; BERTOLINI, G.R.F. MIYAZAKI, J; GAFFURI J., SCHMIDT, R. M. Agricultura familiar: uma alternativa para o desenvolvimento sustentável. Disponível em: <http://cac-php.unioeste.br/projetos/gpps/midia/ seminario2/trabalhos/economia/meco05.pdf > . Acesso em: 16 jun. 2014. 
TVARDOVSKAS.L. Coelho. São Paulo, 2012. Disponívelem: < http://revistagloborural. globo.com/Glo > . Acesso em: 11 mar. 2014.

VELASQUEZ, F.; PLAZA, J.; GUTIERREZ, B.; RODRIGUEZ, G.; ROMERO, M.; XICCATO, G.; TROCINO, A. Italy, a system of integrated rabbit production. Livro de Comunicações do II Congresso Ibérico de Cunicultura, 2007. p. 175-184.

VIEIRA, M. I. Carne de Coelho. Rural News 2008. Disponível em:<http://www. acbc.org.br/images/stories/Manual_prtico_de_cunicultura_2_parte $>$. Acesso em:19 abr. 2014.

WANDERLEY, N. Raízes históricas do campesinato brasileiro. In: TEDESCO (Org.). Agricultura familiar: realidades e perspectivas. Passo Fundo, RS: UPF, 2001, 405p.

WILLIAMS, P.G. Nutritional composition of red meat. Nutr. Diet., v. 64, Suppl. 4, p. 113-119, 2007.

ZHANG, F. The rabbit industry in China. Journal of Applied Rabbit Research, v. 12, p. 278-279, 1990.

Recebido em: 06 de agosto de 2014 Aceito em: 13 de fevereiro de 2017 